\title{
Abu Dhabi efforts in facing global warming challenges through urban planning
}

\author{
M. Alameri \& G. Wagle \\ Masdar City, Abu Dhabi, UAE
}

\begin{abstract}
During the past few decades there has been a growing interest from governments, politicians, decision makers, urban planners and engineers to create sustainable communities planned as ideal built environments that provide communities with the highest quality of life style and standards with the lowest carbon footprint within a feasibly economic envelope. This interest is stirred from the recognition of the world's resources decreasing in a way that the supplies do not match the demand as populations grow and industry spreads. Recent studies are referring to sustainable cities holding the key to climate change. The first of these developments or cities will be a catalyst for future change in understanding the creative science of urban planning. We acknowledge that cities are the outputs of political, economic, geographic and climatic, social and culture inputs. The answers revealed from building sustainable developments such as Masdar city in Abu Dhabi will be the data for forming the basis of future government policies for all developments in the region with similar circumstances and climate and social conditions.

Keywords: global warming, climate change, temperatures, urban planning, sustainable developments.
\end{abstract}

\section{Introduction}

This paper explains how the Masdar Initiative has been conceptualized to be the test bed for technological advancements and setting the standards for sustainable urbanism. The Masdar City development is aimed at demonstrating the principles of sustainable development and shows how an integrated approach to master planning, transportation and infrastructure planning can produce a 
sustainable integrated city where people can live in a safe and secure enhanced environment with reduced impacts which are experienced by inhabitants of traditional cities.

\section{Global warming and climate change - initiative}

The definitions of 'Global Warming' and 'Climate Change' are very broad and vast and have different wordings from one scientist to another. 'Climate Change' is often used interchangeably with the term 'Global Warming'. However, for consistency, it is important to define the terms of use.

'Global Warming' is generally explained as the increase in the average temperature of the Earth's near-surface air and oceans since the mid-20th century and its projected continuation. Most of the observed temperature increase since the middle of the 20th century has been caused by increasing concentrations of greenhouse gases, which result from human activity such as the burning of fossil fuel and deforestation.

'Climate Change' in common parlance, refers to any significant change in measures of climate such as temperature, precipitation, or wind lasting for an extended period - decades or longer. Climate change may result from natural factors, such as changes in the sun's intensity, natural processes within the climate system or human activities that change the land and atmosphere's composition.

The effects of global warming resulting in climate change have had a direct influence on mankind and its existence over centuries. Throughout its five billion year history, environmental change has been transforming the Earth. The records of environmental change are well explained, as revealed by data from various archives such as ocean sediments, ice cores, terrestrial deposits (such as glacial moraines and lake sediments), tree rings and historical and meteorological records. The dynamism of planet earth to adapt to environmental change is especially well illustrated by the changes that have occurred during the past three million years. During this period, cycles of climatic change have been dominant, involving fluctuations in global temperatures by as much as $10^{\circ} \mathrm{Celsius}$ including warm episodes similar to those of the last ten thousand years.

However, it is also the predominant truth that environmental changes have a tremendous impact on the natural ecosystem. The changes in natural ecosystem have had a direct influence on mankind, which are generally explained as the harmful effects. One of the predominant reasons for the negative effects is human activities that change the atmosphere's composition through burning fossil fuels and land degradation through deforestation, reforestation, urbanization, desertification, etc. To alleviate these negative effects, it is very important to respond to climate change with positive measures such as mitigation to reduce emissions, adaptation to the effects of global warming, and geo engineering to remove greenhouse gases from the atmosphere or block incoming sunlight. 


\section{Effects of global warming and climate change on Abu Dhabi}

\subsection{Background}

The United Arab Emirates (UAE) has an area of an approximately 777 sq.km; and a population of 5,671,112 according to the 2009 statistics. The political system of the UAE is based on the 1971 Constitution and comprises several intricately connected governing bodies. It is currently the thirty-sixth largest economy at market exchange rates, and has a high per capita gross domestic product, with a nominal per capita GDP of $\$ 46,584$ as per the International Monetary Fund. The country is the fourteenth largest in purchasing power per capita and has a relatively high Human Development Index for the Asian continent, ranking 35th globally. Abu Dhabi is the largest of the seven emirates which constitutes United Arab Emirates. Abu Dhabi is the political capital of the UAE, positioned off the Arabian Gulf and in the middle of the Middle East. The population is only about 1.4 million people.

\subsection{UAE and its transformations}

UAE has the world's sixth largest oil reserves and is one of the most developed economies in the Middle East. The discovery of $10 \%$ of the world's oil deposits provided an accelerator to bring a major, rapid transformation to his people in various fields - housing, education, health care as well as other essential aspects and social services to the country's nationals and expatriates. The prosperous nation bears responsibility to bring the very best, if not the best of the best to the inhabitants of the place.

\subsection{Urban transformations and its impact}

The discovery of oil primarily in the Emirate of Abu Dhabi was a huge economic boost for the United Arab Emirates. The economic boost not only benefitted Abu Dhabi, but also benefitted the neighboring emirates with Dubai reaching the pinnacle of glory in terms of economic development and urban growth in 2008, before the global downturn. In its efforts to keep abreast with the growing economies of the world, UAE could not be left behind in terms of developmental pressures. In spite of its cautious approach, economic growth of UAE has led to a high influx of manpower which has impacted the scarce available resources. Much has been written about the country's impressive stock of modern buildings, public and private, residential and non-residential, and the country's infrastructure. Nevertheless, very little or in some cases hardly any documentation has been filed on the country's construction industry and the process that was followed to create these facilities. Abu Dhabi has resisted the urge to exhibit its prosperity and has carefully planned its investments so as to ensure a deep connection with heritage; the environment and its people.

Emirate of Abu Dhabi is a confluence of marine and desert environments. A balanced development of both these environments is the key to the success of 
sustainable development of the emirate of Abu Dhabi. The urban settlements of the Emirate of Abu Dhabi are mainly concentrated on the Island area and the immediate vicinity of the island. The rest of the emirate of Abu Dhabi consists of fragile desert ecosystem which is mainly inhabited by the original local inhabitants. Rapid urbanization and its impacts are primarily concentrated in and around the island area, which felt the immediate impacts of urban transformations. The immediate impacts of global warming and climate change likely to affect Abu Dhabi are the rise in sea levels which is accelerating at an alarming pace. There is a plausible concern for sea level change that would actually raise the sea level above the current infrastructure that would imply flooding, essentially.

Leading academics have warned that Abu Dhabi must invest in research and infrastructure if it is to combat the risk of flooding due to climate change. A report earlier this year by the Environmental Agency - Abu Dhabi, entitled 'Climate Change: Impacts, Vulnerability and Adaptation', said that around 85 percent of the population and more than 90 percent of the infrastructure in the UAE was located within several meters of the shoreline, and in low-lying areas. It also stated that "the potential exposure of the UAE, Abu Dhabi in particular, to the impacts of sea level rise given its current socioeconomic conditions in coastal areas is quite significant" [1]. There were two solutions to the threat of rising sea levels: reduce carbon emissions by burning less fossil fuel or "build walls around the perimeter of coastlines and migrate softly inland".

David Holland, director of the Center for Atmosphere Ocean Science at New York University, quoted in Arabian Business - 'The complexity of the problem is that you cannot solve regional sea level change issues until you solve the global one and once you get a handle on the global change then you can figure out what it implies for the region' [1].

It is clearly evident that managing the impacts of sea level rises due to global warming will be the most important task in the next few years.

\section{Role of government in influencing sustainable developments - with specific reference to Abu Dhabi}

Time and again, cities are blamed for the inadequate consumption of our natural resources due to the flaws of design and overlooking of basic factors that would make a significant difference in our planning and utilization of natural resources. However, Urban Planning of cities it's not just related to resources and the environment but also should involve social, economic and political process for it to succeed.

During the past few decades there has been a growing interest from Governments, Politicians, Decision Makers, Urban Planners and Engineers to create sustainable communities planned as ideal built environments that provide communities with highest quality of life style and standards with lowest carbon footprint within a feasibly economic envelope. This interest is stirred from the recognition of the fact that as urban growth increases, world's resources are 
decreasing in a way that the supplies do not match the demand as populations grow and industry spreads.

'Sustainable Urbanism' - With the power of design and an emerging pattern of human settlements, holds the promise of strengthening the interdependence of all life on earth. Many progressive leaders now envision and champion a winwin balance between humanity's need, both social and economic, and those of nature. An increasing number of those leaders recognize the power of thoughtful urbanism to induce people to voluntarily live a more human powered and less resource intensive lifestyle. A small but fast growing number of leaders are now beginning to recognize opportunities to enhance the inherent sustainability of a walk able, diverse urbanism integrated with high-performance buildings and infrastructure [2].

The importance of environmental and ecological sustainability was well understood by the leadership of Abu Dhabi. Quoting the thoughts of Late Sheikh Zayed Bin Sultan Al Nahyan:

'We cherish our environment because it is an integral part of our country, our history and our heritage. On land and in the sea, our forefathers lived and survived in this environment. They were able to do so only because they recognized the need to conserve it, to take from it from it only what they needed to live, and to preserve it for succeeding generations.'

These thoughts clearly underline the thoughts of Abu Dhabi's leadership and their keenness in promoting the sustainable development of Abu Dhabi. Abu Dhabi is committed to taking its part in the global effort to combat climate change. The Emirate's leadership recognizes its responsibility to be a part of concerted international efforts to reduce the volume of greenhouse gases released into the atmosphere - through development of renewable energy, reducing demand for power and addressing the carbon produced by industry, utilities and transport. The government of Abu Dhabi has directly committed itself to strengthen and develop four key priority areas:

- Economic development.

- Social and human resources development.

- Infrastructure development and environmental sustainability.

- Optimization of Government operations.

Developing appropriate infrastructure, while preserving the environment, forms one of the key priority areas.

\section{Abu Dhabi plan 2030 and the initiative to promote sustainable developments}

The Abu Dhabi Urban Planning Council which was created by Emiri Decree number 23 of the year 2007 and is the agency responsible for the future of Abu Dhabi's urban environments, and the expert authority behind the visionary Plan Abu Dhabi 2030 Urban Structure Framework Plan published in September 2007. Chaired by His Highness Sheikh Mohammed Bin Zayed Al Nahyan, Crown Prince of Abu Dhabi and Chairman of the Abu Dhabi Executive Council, the Abu Dhabi Urban Planning Council defines the shape of the Emirate, ensuring 
factors such as sustainability, infrastructure capacity, community planning and quality of life, by overseeing development across the city and the Emirate as a whole. The Abu Dhabi Urban Planning Council ensures best practice in planning for both new and existing urban areas.

Abu Dhabi Urban Planning Council (UPC) is the driving force behind the initiate, drive and supporting Abu Dhabi's urban development strategy. They have transformed Abu Dhabi's 2030 Vision to physical settings, developing strategic development plans that create guiding principles which cascade over critical projects designed to shape the Emirate. The vision is built on a comprehensive analysis of the urban fabric, land availability and its best use, environmental issues, mobility, infrastructure and urban services that need to be integrated in the City Development Strategy. The environmental and ecological context for Abu Dhabi's Urban Structure Plan is directed by three key elements:

- The reality of its landmass existing as an archipelago;

- Its position at the intersection of desert and coast; and

- The uniqueness of an abundance of fossil fuels [3].

With the expertise of the Abu Dhabi Urban Planning Council, the government will ensure the development of a professionally designed and well-managed urban environment in the Emirate's towns and cities complete with world-class traffic and transport systems. The simultaneous development of the Regions is to keep pace with that of the Capital. It is also an important policy priority to achieve an Emirate-wide distribution of economic activities and associated benefits. The Plan Abu Dhabi 2030 Urban Structure Framework Plan [3], which offers a vision for the evolution of the city over the next 25 years, provides a blueprint for Abu Dhabi's long-term success. As the first planning program of this kind and scope within the region, the work of the Urban Planning Council will become a best-practice benchmark for future urban design within the UAE and beyond.

\section{Masdar city as an exemplar for sustainable development}

\subsection{Masdar initiative}

As the first major hydrocarbon-producing economy to take such a step, Abu Dhabi has established its leadership position by launching the MASDAR Initiative. The MASDAR Initiative driven by the Abu Dhabi Future Energy Company, a wholly owned subsidiary of the Mubadala Development Company is a global cooperative platform for the open engagement in the search for solutions to some of mankind's most pressing issues - energy security, climate change and the development of human expertise in sustainability.

Abu Dhabi is leveraging its substantial resources and experience in global energy markets into the technologies of the future. One key objective of MASDAR is to position Abu Dhabi as a world-class research and development hub for new energy technologies, effectively balancing its strong position in an evolving world energy market. A related objective is to drive the commercialization and adoption of these and other technologies in sustainable 
energy, water conservation and waste management and in doing so; MASDAR will play a decisive role in Abu Dhabi's transition from technology consumer to technology producer. The goal is to facilitate the establishment of an entirely new economic sector in Abu Dhabi around these new industries, which will assist economic diversification and the development of knowledge-based industries, while enhancing Abu Dhabi's existing record of environmental stewardship and its contribution to the global community. Firmly networked into the global economy, these industries will transform Abu Dhabi's economic role and will contribute to the development of national and regional economies. When that is accomplished, Abu Dhabi will then have completed its transition from a 20th century, carbon-based economy into a sustainable 21 st century hightechnology economy. It will also be setting the pace as a global leader in the energy industry, in technology and in sustainability. Masdar Initiative signals a bold commitment to renewable energy and sustainable technologies that will enable the emirate of Abu Dhabi to remain a global energy industry leader to prepare its citizens for a post-oil future and help mankind find a development model that is sustainable.

\subsection{Masdar city - setting the standard for sustainable developments}

Masdar City is the physical embodiment of the Masdar Initiative. Fully rooted to the principles defined in Plan Abu Dhabi 2030 vision, Masdar City is committed to advancing Abu Dhabi's drive towards a sustainable Arab capital that focuses on:

- Advancing renewable energy technologies

- Mitigating climate change

- Diversifying the economy

- Preparing Abu Dhabi for a clean energy future.

Sustainable cities hold the key to climate change. The first of these developments or cities will be a catalyst for future change in the understanding the creative science of urban planning. The answers revealed from building sustainable developments such as Masdar City will be the data for forming the basis of future government policies for all developments in the region with similar circumstances and climate and social conditions.

Aspiring to be one of the most sustainable communities on the planet, Masdar City not only embodies Abu Dhabi's commitment to a sustainable future, it is the place where best practice in sustainable urban planning and development is being developed, tested and deployed. It provides an attractive environment for cleantech firms, academic institutions, research facilities, financial firms and other organizations to collaborate and develop new technologies and solutions.

\subsection{Masdar city - location and context}

Masdar's development site of approximately 600 hectares supports sustainable planning considerations in terms its strategic location adjacent to the principal urban and regional transport infrastructure of Abu Dhabi. It is located between the principal access roads, Airport Road and Abu Dhabi-Dubai Road, linking 
Abu Dhabi to the airport and to Dubai beyond. Further, its immediate adjacency to the international airport gives the Masdar development significant potential to become a strategic and emblematic gateway into Abu Dhabi. As such, the Masdar development has the capacity to be the first and parting emblem of Abu Dhabi's sustainable development and environmentally sensitive socio-economic growth.

\subsection{Masdar city - master plan}

Conceptualized on the principles on One Planet Living, the master plan for Masdar City aims to establish the world's first carbon neutral, zero waste desert community. It is rooted in a sense of place, shaped by the specific climate of Abu Dhabi. It is inspired by traditional desert settlements, which are compact and oriented so that the buildings provide shade and the narrow compact streets channelize cooling air currents. The project is an opportunity to start from scratch to actively minimize energy demand through the planning and orientation of the urban grid. In this way, it goes far beyond reducing the environmental impact of an individual building. Working at the scale of the integrated city, it addresses housing, education, work, transport and infrastructure, energy, water, and issues of density together, with the aim of achieving a carbon neutral, sustainable community.

The goal of Masdar is to provide residents with the highest quality of life with the lowest environmental footprint. To achieve this goal the City is based on the principles of sustainable urban design:

- Low rise high density accommodation.

- Sustainable transportation.

- Dense Neighborhoods.

- Controlled spread of development [4].

The Masterplan proposes the use of current and emerging technologies at an unprecedented scale.

\subsubsection{Urban design}

Masdar City is conceived as a modern Arabian city, with a focus on developing the sustainable technologies of the future. The master plan design relies on passive environmental controls, using the buildings' orientation and compact form to reduce energy demand naturally.

Masdar City is inspired by the first cities of the Middle East which were models of sustainable development and largely self-sufficient. Their fabric and orientation was dictated by locally available materials and the climate and more importantly, walk able cities. The compact city form to maximize shade and walk ability may have resulted into high density developments. Masdar City has adopted this model, rejecting the more recent model of urban planning that revolves around the personalized vehicle and the transportation network.

The city's urban fabric is defined by two city squares - the large square, approximately 225 Hectares and the small square, approximately 52 Hectares in size. The City squares are also characterized by linear parks which are oriented 
in the direction of wind movements and facilitate the wind movement through the city squares. The land surrounding the city squares contains photovoltaic farms, research fields, utility structures and recreation areas, allowing the community to be entirely self-sufficient. The buildings are low-rise and the development is completely integrated where residents find everything they need close to hand.

\subsubsection{Transportation}

Masdar City is a true demonstration of the concept of sustainable transportation. Transportation plays a pivotal role in sustainability and truly efficient transportation - walking, bicycling, and transit use - is only possible where there is compact, urban form. In keeping with the form of traditional Arab communities, Masdar City incorporates narrow streets, shaded pathways and courtyards. These create an attractive, comfortable pedestrian environment and, at any point in the city, the nearest public transport link is conveniently within a 250 meter range.

One of Masdar's aims is to provide a test-bed for innovative concepts and systems, and this is demonstrated through the complete integration of walking and cycling with five public transport systems within and outside the city:

- The driverless Personalized Rapid Transit (PRT) system linking Masdar Institute to its car park.

- The orbital Group Rapid Transit (GRT) system that is positioned encircling the city's centres providing easy access to the citywide fabric.

- The LRT through the city providing access from outside and distribution within Masdar forms the spine of the city.

- The Metro that will provide a direct service into Masdar from Abu Dhabi's CBD and other parts of Abu Dhabi city.

- The point-to-point premium service using electrically powered E-taxis for direct travel in the city for those who cannot or do not want to use the other systems.

It is introducing a new age of public transport provision that offers a safe and clean way of reaching your destination.

\subsubsection{Infrastructure}

In the industrialized world, buildings and the activities within them consume roughly a third of the energy we generate and produce a third of the carbon dioxide emissions. Together, the combination of buildings and infrastructure accounts for almost three quarters of the energy consumed in an industrialized society. A holistic approach is therefore needed, which looks at infrastructure and buildings in an integrated way - to be effective, such an approach requires a bold political initiative.

Masdar City's energy strategy addresses demand as well as power generation and incorporates a range of strategies designed to promote a sustainable way of life. Once fully built, Masdar City will be fully powered by renewable energy, and solar power will satisfy the majority of energy required. The city's power needs will be substantially lower than conventional cities in the region. A 10MW 
solar photovoltaic plant is already operational within Masdar City. In addition to solar energy, Masdar City is exploring the viability of geothermal, waste-toenergy and solar cooling technologies that use the power of the sun to run airconditioning units.

Masdar City's water needs will be less than half that of conventional cities in the region. To achieve this, the city employs a broad array of technologies to reduce water consumption, including high efficiency appliances, smart water meters and highly efficient irrigation systems. Wastewater will be treated at the city's wastewater treatment plant and treated water will be re-cycled for irrigation.

Masdar City waste strategy aims at significantly reducing waste, encouraging a low-waste lifestyle through the reduction, reuse, recycling and recovery of waste materials. Most waste that cannot be recycled will be treated in a thermal treatment plant, where it can be converted to energy.

Sustainable Urbanism is the need of the hour. The integrated design of landuse, transportation and infrastructure is the cornerstone of the principles of sustainable urbanism. Time is the essence in adopting the reforms of sustainable urbanism. Masdar City is a challenge requiring original thinking and advanced technological solutions, but it offers a compelling opportunity for a thorough scrutiny of the reforms for sustainable urbanism. Masdar City, as a fundamental component of the Masdar Initiative, needs to be understood as a long-term initiative that may challenge many principles informing conventional planning in order to establish a truly sustainable urban development. By embracing this challenge in such an extreme climate, the Masdar City aims at demonstrating the concepts of a sustainable development for both new and existing cities not only in the Middle East but around the world.

\section{References}

[1] Arabian Business; www.arabianbusiness.com

[2] Farr, Douglas; Sustainable Urbanism: Urban Design with Nature; John Wiley \& Sons, Inc., Hoboken, New Jersey; 2008

[3] Abu Dhabi Urban Planning Council; Plan Abu Dhabi 2030; Abu Dhabi Urban Planning Council; September 2007

[4] Foster+Partners; Detailed Masterplan for Masdar City; January 2008 